\title{
Direct observation of size dependent activation of NO on gold clusters $\dagger$
}

\author{
André Fielicke, ${ }^{a}$ Gert von Helden, ${ }^{a}$ Gerard Meijer, ${ }^{a}$ Benoit Simard ${ }^{b}$ and David M. Rayner ${ }^{* b}$ \\ ${ }^{a}$ Fritz-Haber-Institut der Max-Planck-Gesellschaft, Faradayweg 4-6, D-14195 Berlin, Germany. \\ E-mail:fielicke@fhi-berlin.mpg.de \\ ${ }^{b}$ Steacie Institute for Molecular Sciences, National Research Council, 100 Sussex Drive, \\ Ottawa,Ontario, CanadaK1A0R6.E-mail: david.rayner@nrc-cnrc.gc.ca
}

Received 17th August 2005, Accepted 11th October 2005

First published as an Advance Article on the web 25th October 2005

\begin{abstract}
Vibrational spectra of NO ligands adsorbed on cationic gold clusters are obtained using IR multiphoton dissociation spectroscopy. We observe a strong oscillation of the NO stretching frequency with increasing cluster size that reveals a clear odd-even dependence in the strength of the NO bond. For the corresponding CO complexes, no oscillation is found. This behaviour can be understood on the basis of the character and occupation of the frontier orbitals of the complexes.
\end{abstract}

Small transition metal clusters or nanoparticles often show fascinating catalytic properties. This is true not only for "traditional" catalyst metals, such as rhodium or platinum, but also for gold that is usually thought of as being inert because of its bulk state properties. A striking example for this activity is the catalysis of the oxidation of carbon monoxide by molecular oxygen by $\mathrm{Au}_{8}$ supported on $\mathrm{MgO} .{ }^{1}$ More generally there is a significant interest in understanding the mechanism of catalytic reactions and specifically in oxidation reactions on late transition metals. Technologically important examples are the catalytic treatment of motor vehicle exhaust gas using a $\mathrm{Pt}-\mathrm{Pd}-\mathrm{Rh}$ catalyst ${ }^{2}$ or the selective epoxidation of ethylene on silver catalysts. $^{3}$

Most of the mechanisms for metal activated oxidation reactions occurring on the surfaces of metals or on clusters in the gas phase are based on the initial activation of the oxidant molecule, e.g. $\mathrm{O}_{2}$ or $\mathrm{NO}$, by donation of electrons into its antibonding orbitals. ${ }^{4}$ The activity of an oxidation catalyst is therefore related to the electron density on the metal particle. This electron transfer formally leads to superoxide $\left(\mathrm{O}_{2}{ }^{-}\right)$or peroxide $\left(\mathrm{O}_{2}{ }^{2-}\right)$ intermediate species in the case of $\mathrm{O}_{2}$ and to $\mathrm{NO}^{-}$for NO. For instance, in the case of small deposited gold clusters it has been found that the available partial charge on the cluster plays a significant role in determining catalytic activity. ${ }^{1}$

Recently, some information on the nature of adsorbed oxygen species on gold clusters has been obtained by vibrationally resolved UV photoelectron spectroscopy of the anionic complexes $\mathrm{Au}_{n} \mathrm{O}_{2}{ }^{-5} \cdot{ }^{5}$ For sizes of $n=2,4$, and 6 vibrational modes at $\sim 1440,1230$, and $1450 \mathrm{~cm}^{-1}$, respectively, have been found-frequencies that lie between typical values for the $\mathrm{O}-\mathrm{O}$ stretch vibration of superoxides $\left(\sim 1150 \mathrm{~cm}^{-1}\right)$ and for free molecular oxygen $\left(1555 \mathrm{~cm}^{-1}\right)$. However, because of the low reactivity of anionic gold clusters with an odd number of $\mathrm{Au}$

$\dagger$ Electronic supplementary information (ESI) available: Details of the structures, energetics and vibrational frequencies of the $\mathrm{Au}_{n} \mathrm{NO}^{+}$and $\mathrm{Au}_{n} \mathrm{CO}^{+}$complexes from DFT calculations.. See DOI: 10.1039/ $\mathrm{b} 511710 \mathrm{k}$ atoms towards $\mathrm{O}_{2}$, only the cluster complexes $\mathrm{Au}_{n} \mathrm{O}_{2}{ }^{-}$with even $n$ have been characterized.

Here, we make a direct measurement of the degree of activation of $\mathrm{NO}$ adsorbed on small gold cluster cations in the gas phase as a function of cluster size by measuring the NO stretching frequency, $\nu(\mathrm{NO})$. This frequency is directly related to the force constant of the $\mathrm{N}-\mathrm{O}$ bond and hence to its strength. We find a pronounced alternating dependence of $\nu(\mathrm{NO})$ on the number of gold atoms in the cluster, $n$, with the even $n$ complexes having a lower $\nu(\mathrm{NO})$ and hence a weaker $\mathrm{N}-\mathrm{O}$ bond. This alternation is reproduced by density functional theory, DFT, and a resulting molecular orbital analysis shows that the low $\nu(\mathrm{NO})$ on the even $n$ clusters correlates with double occupancy of the NO $2 \pi^{*}$ orbital, whereas the higher $\nu(\mathrm{NO})$ on odd $n$ clusters correlates with single occupancy. In comparison, the stretching frequency of $\mathrm{CO}, \nu(\mathrm{CO})$, adsorbed on the same cationic gold clusters shows no odd-even dependence on $n$, reflecting the metal centred nature of the HOMO in $\mathrm{Au}_{n} \mathrm{CO}^{+}$complexes.

We obtain the vibrational spectra of gas phase gold cluster complexes by infrared (IR) multiphoton dissociation spectroscopy. The experimental methods are similar to those used earlier in our investigations of transition metal cluster carbonyls. ${ }^{6,7}$ The cluster cations are produced in a laser ablation source and reacted with $\mathrm{NO}$ or $\mathrm{CO}$ prior to expansion to form a molecular beam. They are detected downstream using timeof-flight mass spectrometry. Prior to detection they are subjected to intense IR laser radiation that causes dissociation of the ligand when resonant with an IR active mode. Mass spectra are collected as a function of laser frequency and IR absorption by a specific complex is registered by depletion of its peak in the mass spectrum. The reagent gas pressure is adjusted so that there is no interference in the resulting IR spectra from complexes with more than one ligand attached. The experiments make use of the Free Electron Laser for Infrared eXperiments $\left(\right.$ FELIX) ${ }^{8}$ at the FOM Institute for Plasmaphysics "Rijnhuizen" in Nieuwegein, the Netherlands.

Fig. 1 shows the IR depletion spectra of small gold cluster cations with a single NO molecule adsorbed. The IR absorption band, that ranges between 1780 and $1860 \mathrm{~cm}^{-1}$, is identified as NO atop bound in a nitrosyl complex by comparison with known coordination compounds. ${ }^{9}$ The odd-even oscillation in $\nu(\mathrm{NO})$ that is immediately apparent continues out to at least $n=20$, the extent of our measurements, as shown in Fig. 2(a). Fig. 2(a) also shows $\nu(\mathrm{CO})$ for some monocarbonyl $\mathrm{Au}_{n} \mathrm{CO}^{+}$complexes measured in the same way. These species show no odd-even oscillation. A related odd-even oscillation has been reported in the relative binding energy of $\mathrm{O}_{2}$ with anionic gold clusters as estimated from 


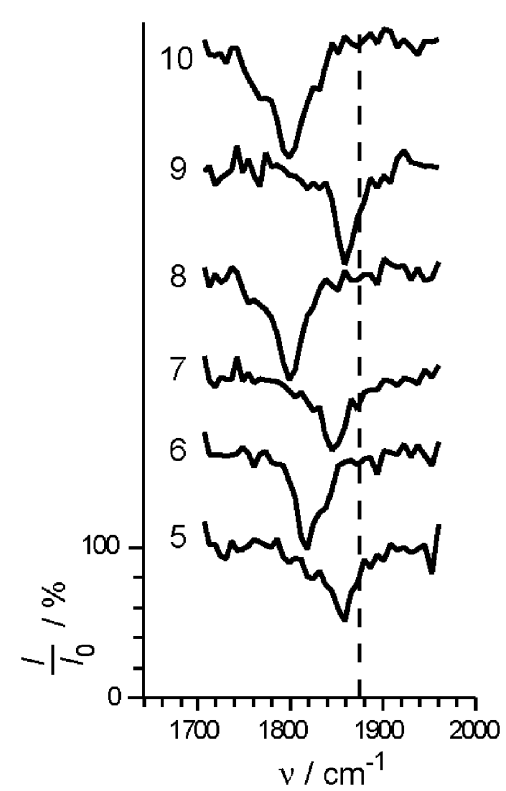

Fig. 1 IR multiphoton dissociation spectra of the NO complexes of cationic gold clusters $\mathrm{Au}_{n} \mathrm{NO}^{+}(n=5-10)$. The dashed line indicates the frequency of the stretching vibration of free NO.

reaction studies made under equilibrium control. ${ }^{4 e}$ Through correlation with the $\mathrm{Au}_{n}{ }^{-}$electron affinities, it was argued effectively that the biradical $\mathrm{O}_{2}$ acts as an one-electron acceptor and that the stronger bonding of $\mathrm{O}_{2}$ to odd-electron clusters results from pairing of electrons.

In coordination chemistry, the formalism that the NO ligand can bind as either $\mathrm{NO}^{+}$or as $\mathrm{NO}^{-}$is used to understand the

(a)

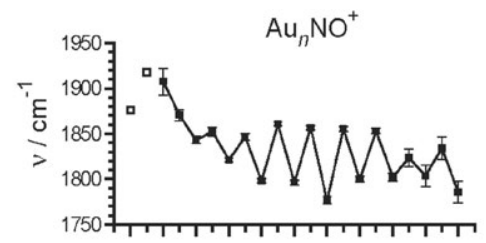

(b)

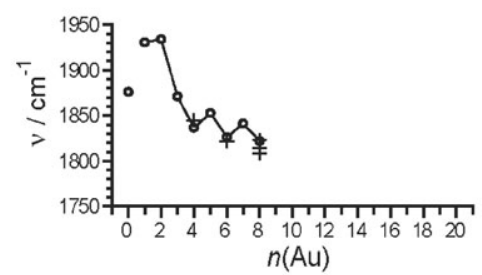

(c)
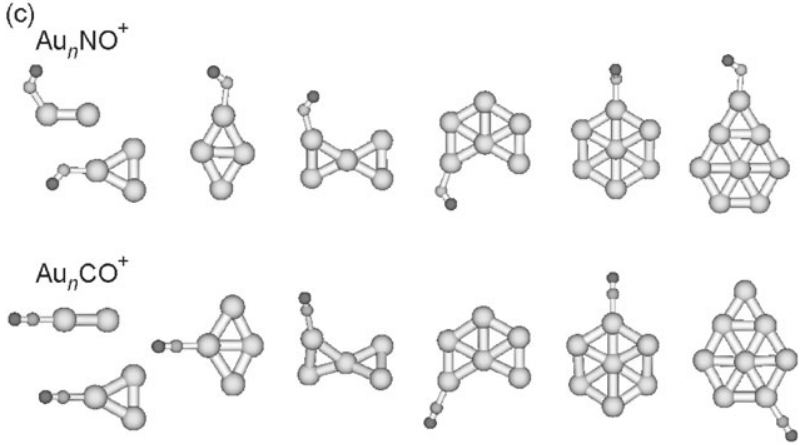

Fig. 2 Properties of $\mathrm{Au}_{n} \mathrm{NO}^{+}$and $\mathrm{Au}_{n} \mathrm{CO}^{+}$complexes. (a) Plots of the experimentally determined frequencies for the internal ligand stretches. Empty squares indicate the values for the free ligands and atomic gold complexes measured in rare gas matrices. ${ }^{10}$ The calculated frequencies of the ligand stretch vibrations of the complexes are shown in (b). The frequencies of the lowest energy structures are shown as circles. The crosses mark the frequencies of low-lying structures with the ligand bound in alternative atop positions. The calculated structures of the lowest energy complex are depicted in (c). existence of the two main classes of nitrosyl compound that were initially distinguished by the degree of bending in the $\mathrm{M}-\mathrm{N}-\mathrm{O}$ coordinate. ${ }^{9}$ In other words, NO can act either as an electron acceptor or an electron donor. Under this formalism, weakening of the NO bond, as indicated by lowering of $\nu(\mathrm{NO})$, is indicative of the ligand binding as $\mathrm{NO}^{-}$, due to the electron transfer increasing the occupancy of the $\pi^{*}$ antibonding HOMO of NO. The odd-even oscillation in $\nu(\mathrm{NO})$ is then simply understood through NO acting as an electron acceptor, with this interaction being significantly stronger for odd-electron $\mathrm{Au}$ clusters due to energy gains from electron pairing.

$\mathrm{Au}_{2} \mathrm{NO}^{+}$is a special case. Although it contains an even number of gold atoms, it breaks the odd-even pattern with $\nu(\mathrm{NO})$ even higher than in free NO $\left(1876 \mathrm{~cm}^{-1}\right)$. Indeed, the fact that we observe $\mathrm{Au}_{2} \mathrm{NO}^{+}$at all is also indicative of a different binding mechanism. Doubly charged $\mathrm{Au}_{2}{ }^{2+}$ is calculated to be unbound leading to the expectation that the reaction with $\mathrm{NO}$ acting as an electron acceptor would lead to dissociation of the $\mathrm{Au}-\mathrm{Au}$ bond. We propose that the strengthening of the $\mathrm{NO}$ bond in $\mathrm{Au}_{2} \mathrm{NO}^{+}$, as indicated by $\nu(\mathrm{NO})$, is indicative of the ligand binding as $\mathrm{NO}^{+}$, i.e. the binding of $\mathrm{NO}$ to $\mathrm{Au}_{2}{ }^{+}$involves transfer of an electron from the $\pi^{*}$ orbital of the NO to formally fill the hole in the HOMO of $\mathrm{Au}_{2}{ }^{+}$. The electron transfer is feasible since the IP of $\mathrm{Au}_{2}$ $(\sim 9.5 \mathrm{eV})$ is higher than that of $\mathrm{NO}$, whereas all larger clusters have clearly lower IPs than NO. ${ }^{11}$

To support our vibrational assignments and to develop a more complete frontier orbital picture of NO binding, we have carried out DFT calculations on the properties of the complexes of the gold cluster cations $\mathrm{Au}_{n}{ }^{+}$up to $n=8$ with $\mathrm{NO}$ and, for comparison, $\mathrm{CO}$. Calculations on $\mathrm{Au}_{n} \mathrm{NO}^{+}$have been reported before, however the observed oscillations in $\nu(\mathrm{NO})$ are not reproduced. ${ }^{12}$ The calculations on $\mathrm{Au}_{n} \mathrm{CO}^{+}$agree mostly with earlier calculations. ${ }^{13}$ The planar geometries of the bare metal clusters are well established from ion mobility measurements ${ }^{14}$ and CO saturation studies. ${ }^{15}$ Moreover, the saturation studies show that the clusters retain their overall structure under the addition of successive $\mathrm{CO}$ molecules up to saturation. This means that the addition of a single $\mathrm{CO}$ or NO is not expected to cause isomerization of the cluster and extensive searches for structures with substantially rearranged cluster cores are not necessary. The structures of a comprehensive range of complexes with $\mathrm{NO}$ or CO initially adsorbed on different sites of the clusters, including atop $\left(\mu^{1}\right)$ bridging $\left(\mu^{2}\right)$ and three-fold $\left(\mu^{3}\right)$ arrangements, have been fully optimized, including the Au atom coordinates, using the TURBOMOLE V5-7 DFT program package of Ahlrichs and coworkers $^{16}$ using the included TZVP basis sets, the B3LYP functional and a relativistic effective core potential ${ }^{17}$ for the gold atoms.

We find that $\mathrm{NO}$ and $\mathrm{CO}$ bind exclusively in an atop arrangement and tend to favour low coordinated gold atoms. The lowest energy geometries are shown in Fig. 2(c). The only other stable structures found are also atop complexes, but with the ligand $\mu^{1}$ bound to alternative edge $\mathrm{Au}$ atoms. The $\mathrm{CO}$ occupies the same sites as NO in most of the corresponding CO complexes, however it is always linearly bound. Details of the structures, energetics and vibrational frequencies of all calculated complexes are available as supplementary information. $\dagger$ The calculated ligand binding energies for the low lying complex structures are between -0.8 and $-1.9 \mathrm{eV}$ for $\mathrm{Au}_{n} \mathrm{CO}^{+}$and -0.5 and $-1.4 \mathrm{eV}$ for $\mathrm{Au}_{n} \mathrm{NO}^{+}$. The calculations started in $\mu^{2}$ and $\mu^{3}$ arrangements always converged to atop structures except in the case of the $\mu^{2} \mathrm{Au}_{3}{ }^{+}$complexes. These converged to a transition state between two atop structures lying close in energy to the separate reactants.

The calculated $\nu(\mathrm{NO})$ and $\nu(\mathrm{CO})$ values are shown in Fig. 2(b). These stretching frequencies are scaled by a constant factor derived from the ratios of the experimental and calculated vibrational frequencies of the free ligand molecules 

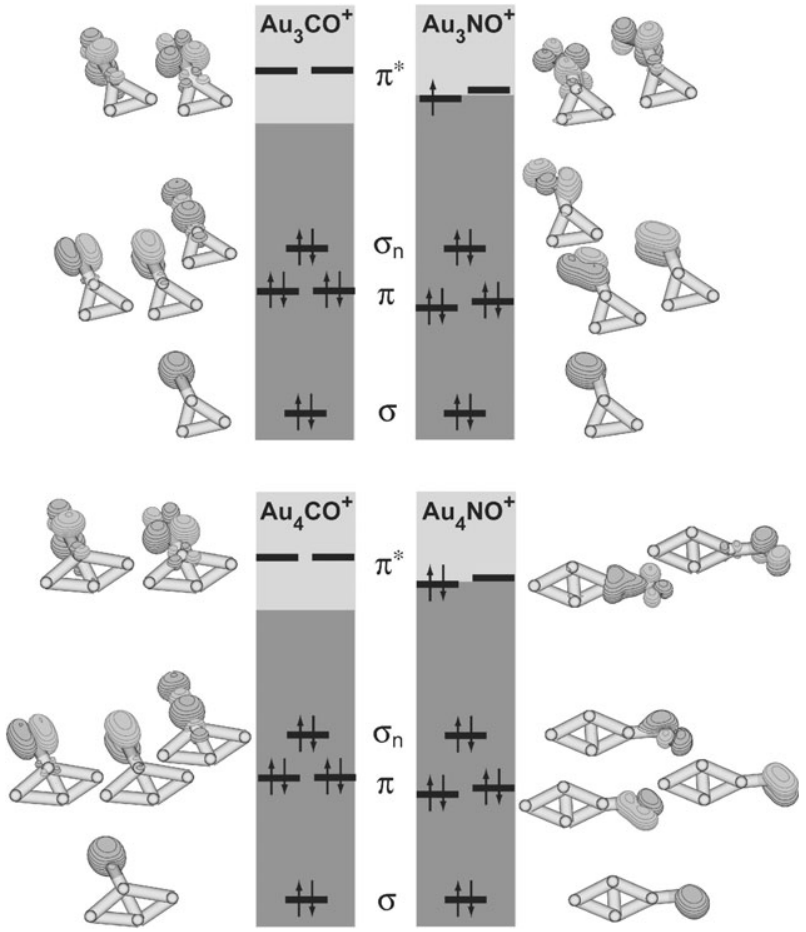

Fig. 3 Molecular orbital schemes for the NO and CO complexes of $\mathrm{Au}_{3}{ }^{+}$and $\mathrm{Au}_{4}{ }^{+}$. The density plots for the ligand localized orbitals and energy level ordering are from DFT calculations, although the relative energies are only indicated qualitatively. The energy ranges of the occupied metal centred orbitals are indicated by dark grey shading (dark blue in html).

( 0.9506 for NO, 0.9671 for CO). There is good agreement with the experimental values of the internal stretching frequencies, confirming the spectroscopic assignment of $\nu(\mathrm{NO})$ and $\nu(\mathrm{CO})$ to atop bound ligands by comparison with known coordination compounds. In particular, the oscillations of $\nu(\mathrm{NO})$ for the complexes of odd and even numbered gold clusters are reproduced, whereas for the CO complexes no oscillation is found. This conclusion holds even if we consider the frequencies for the other low lying atop isomers, as $\nu(\mathrm{NO})$ and $\nu(\mathrm{CO})$ are not markedly sensitive to the particular atop site occupied.

The bonding situation in the $\mathrm{NO}$ and $\mathrm{CO}$ complexes is illustrated using molecular orbital schemes in Fig. 3. We only depict those orbitals that have a strongly ligand centred character and that can be related to the corresponding orbitals of the free ligands. The relative energies and occupation numbers prove to be very similar for the energetically low lying $\sigma, \pi$ and $\sigma_{n}$ orbitals of $\mathrm{NO}$ and $\mathrm{CO}$, however, there are pronounced differences for the $\pi^{*}$ orbitals. In case of the NO complexes one $\pi^{*}$ orbital forms the HOMO, whereas for the CO complexes both the HOMO and the LUMO are metal centred orbitals. For the $\mathrm{CO}$ ligands the $\pi^{*}$ orbitals are significantly higher in energy ( 6.0 and $4.4 \mathrm{eV}$ above the HOMO for $\mathrm{Au}_{3} \mathrm{CO}^{+}$and $\mathrm{Au}_{4} \mathrm{CO}^{+}$, respectively). Due to these high energies the $\pi^{*}$ orbitals of the CO ligands barely interact with filled metal centred orbitals of the gold cluster. As a consequence, the back-donation from the metal into the $\pi^{*}$ orbitals is much less important for the binding of the CO ligands than it is in most other transition metal carbonyls. For the NO complexes the $\pi^{*}$ orbital forming the HOMO is singly occupied for gold clusters $\mathrm{Au}_{n}{ }^{+}$with an odd number of atoms and doubly occupied for even $n$. Therefore, the formal bond order of the NO is oscillating between 2.5 and 2. This oscillation in the bond strength is associated with an oscillation in the stretching force constant that is observed in the vibrational spectra.

In the case of $\mathrm{Au}_{2} \mathrm{NO}^{+}$the $\mathrm{HOMO}$ has less pronounced $\pi^{*}$ character and is mainly centred at the $\mathrm{Au}$ atom not binding to the $\mathrm{NO}$, as expected when $\mathrm{NO}$ acts as an electron donor. As a result, the binding situation in $\mathrm{Au}_{2} \mathrm{NO}^{+}$is more similar to that in the carbonyls, with the vacated $\pi^{*}$ orbitals forming the LUMO and LUMO +1 orbitals. The different binding behaviour also affects other molecular properties. The NO bond length in $\mathrm{Au}_{2} \mathrm{NO}^{+}$is calculated to be $1.11 \AA$, clearly shorter than in the larger complexes where it is calculated to be in the range of 1.13-1.14 $\AA$. The NO is also much stronger bound with a binding energy of $\sim 1.4 \mathrm{eV}$, whereas that value is within $0.5-0.8 \mathrm{eV}$ for the larger cluster nitrosyls. Interestingly, the calculations predict for the $\mathrm{Au}-\mathrm{N}-\mathrm{O}$ angle in $\mathrm{Au}_{2} \mathrm{NO}^{+}$a value of $127^{\circ}$ that is within the range covered by the larger complexes of $123-129^{\circ}$ (only $\mathrm{AuNO}^{+}$is linear ${ }^{10 a}$ ). This is not too surprising considering the recognized limitations of the formal assignment of the NO complexes to $\mathrm{NO}^{+} v s$. $\mathrm{NO}^{-}$species on the basis of the $\mathrm{M}-\mathrm{N}-\mathrm{O}$ bending angle. ${ }^{9}$

The spectroscopically proven oscillation of the NO bond order implies a size dependence in the ability of NO to oxidize molecules such as $\mathrm{CO}$ on the surface of small gold clusters. So far we have not observed reactions between co-adsorbed $\mathrm{CO}$ and NO molecules on cationic gold clusters at room temperature. Nevertheless, the interaction of NO with gold clusters forms a model for more reactive transition metals, e.g. rhodium, where the catalytic oxidation of $\mathrm{CO}$ by NO is of great interest. $^{3}$ In preliminary experiments we find that rhodium clusters are too reactive at room temperature to capture the molecular NO complex. Related to this, dissociative chemisorption of $\mathrm{NO}$ on $\mathrm{Rh}_{6}{ }^{+}$has recently been deduced from ion trap experiments. ${ }^{18}$ On gold at elevated temperatures one may expect also to induce dissociation of NO that could be probed by a disappearance of the $\nu(\mathrm{NO})$ band. Thus we propose the cationic gold clusters as a model system to study the size and temperature dependent reactivity of $\mathrm{NO}$ or similar oxidants.

\section{Acknowledgements}

We gratefully acknowledge the support of the Stichting voor Fundamenteel Onderzoek der Materie (FOM) in providing beam time on FELIX and the skilful assistance of the FELIX staff, in particular Dr A. F. G. van der Meer and Dr B. Redlich.

\section{References}

1 (a) A. Sanchez, S. Abbet, U. Heiz, W.-D. Schneider, H. Häkkinen, R. N. Barnett and U. Landman, J. Phys. Chem. A, 1999, 103, 9573-9578; (b) B. Yoon, H. Häkkinen, U. Landman, A. S. Wörz, J.-M. Antonietti, S. Abbet, K. Judai and U. Heiz, Science, 2005, 307, 403-407.

2 M. Shelef and G. W. Graham, Catal. Rev. Sci. Eng., 1994, 36, 433- 457.

3 J. G. Serafin, A. C. Liu and S. R. Seyedmonir, J. Mol. Catal. A: Chem., 1998, 131, 157-168.

4 (a) C. N. R. Rao, P. V. Kamath and S. Yashonath, Chem. Phys. Lett., 1982, 88, 13-16; (b) I. Panas and P. Siegbahn, Chem. Phys. Lett., 1988, 153, 458-464; (c) T. H. Lee and K. M. Ervin, J. Phys. Chem., 1994, 98, 10023-10031; (d) M. A. van Daelen, M. Neurock and R. A. van Santen, Surf. Sci., 1998, 417, 247-260; (e) B. E. Salisbury, W. T. Wallace and R. L. Whetten, Chem. Phys., 2000, 262, 131-141; (f) T. M. Bernhardt, Int. J. Mass Spectrom., 2005, 243, 1-29.

5 (a) Y. D. Kim, Int. J. Mass Spectrom., 2004, 238, 17-31; (b) Y. D. Kim, M. Fischer and G. Ganteför, Chem. Phys. Lett., 2003, 377, 170-176; (c) D. Stolcic, M. Fischer, G. Ganteför, Y. D. Kim, Q. Sun and P. Jena, J. Am. Chem. Soc., 2003, 125, 2848-1849; (d) Q. Sun, P. Jena, Y. D. Kim, M. Fischer and G. Ganteför, J. Chem. Phys., 2004, 120, 6510-6515.

6 (a) A. Fielicke, G. von Helden, G. Meijer, D. B. Pedersen, B. Simard and D. M. Rayner, J. Phys. Chem. B, 2004, 108, 1459114598; (b) A. Fielicke, G. von Helden, G. Meijer, B. Simard, S. Dénommée and D. M. Rayner, J. Am. Chem. Soc., 2003, 125, 11184-11185.

7 A. Fielicke, G. von Helden, G. Meijer, D. B. Pedersen, B. Simard and D. M. Rayner, J. Am. Chem. Soc., 2005, 127, 8416-8423. 
8 D. Oepts, A. F. G. van der Meer and P. W. van Amersfoort, Infrared Phys. Technol., 1995, 36, 297-308.

9 (a) R. Eisenberg and C. D. Meyer, Acc. Chem. Res., 1975, 8 26-34; (b) G. B. Richter-Addo and P. Legzdins, Metal Nitrosyls, Oxford University Press, New York, 1992; (c) K. Nakamoto, Infrared and Raman Spectra of Inorganic and Coordination Compounds Part B, John Wiley \& Sons, Inc., New York, 5th edn, 1997.

10 (a) A. Citra, X. Wang and L. Andrews, J. Phys. Chem. A, 2002, 106, 3287-3293; (b) B. Liang and L. Andrews, J. Phys. Chem. A, 2000, 104, 9156-9164.

11 (a) NIST Chemistry WebBook NIST Standard Reference Database Number 69, ed. P. J. Linstrom and W. G. Mallard, National Institute of Standards and Technology, Gaithersburg, MD, 2005, 20899 (http://webbook.nist.gov); (b) C. Jackschath, I. Rabin and W. Schulze, Ber. Bunsen-Ges. Phys. Chem., 1992, 96, $1200-1204$
12 X. Ding, Z. Li, J. Yang, J. G. Hou and Q. Zhu, J. Chem. Phys., 2004, 121, 2558-2562.

13 (a) M. Neumaier, F. Weigend, O. Hampe and M. M. Kappes, $J$. Chem. Phys., 2005, 122, 104702; (b) X. Wu, L. Senapati, S. K. Nayak, A. Selloni and M. Hajaligol, J. Chem. Phys., 2002, 117, 4010-4015.

14 S. Gilb, P. Weis, F. Furche, R. Ahlrichs and M. M. Kappes, J. Chem. Phys., 2002, 116, 4094-4101.

15 A. Fielicke, G. von Helden, G. Meijer, D. B. Pedersen, B. Simard and D. M. Rayner, J. Am. Chem. Soc., 2005, 127, 8416-8423.

16 R. Ahlrichs, M. Bär, M. Häser, H. Horn and C. Kölmel, Chem. Phys. Lett., 1989, 162, 165-169.

17 D. Andrae, U. Haeusermann, M. Dolg, H. Stoll and H. Preuss, Theor. Chim. Acta, 1990, 77, 123-141.

18 M. S. Ford, M. L. Anderson, M. P. Barrow, D. P. Woodruff, T. Drewello, P. J. Derrick and S. R. Mackenzie, Phys. Chem. Chem. Phys., 2005, 7, 975-980. 